\title{
DINÂMICA DO ACÚMULO DE MATÉRIA SECA EM PASTAGENS DE TIFTON 85 SOB PASTEJO
} \author{
Guilherme Silveira Pedreira² \\ ${ }^{1}$ Pós-Graduandos do Depto. de Produção Animal - USP/ESALQ. \\ ${ }^{2}$ Depto. de Produção Animal - USP/ESALQ, C.P. 9 - CEP: 13418-900 - Piracicaba, SP. \\ ${ }^{3}$ Bolsista FAPESP. \\ ${ }^{4}$ Bolsista CAPES. \\ *Autor correspondente <scdsilva@carpa.ciagri.usp.br>
}

Luiz Felipe de Moura Pinto ${ }^{1,4}$; Sila Carneiro da Silva ${ }^{2 \star}$; André Fischer Sbrissia ${ }^{1,3}$; Carlos Augusto Brandão de Carvalho ${ }^{1,3}$; Roberta Aparecida Carnevalli1,4; Jaílson Lara Fagundes ${ }^{1,4}$; Carlos

\begin{abstract}
RESUMO: O acúmulo de forragem é o resultado líquido de dois processos concomitantes e antagônicos: o crescimento e a senescência e morte de tecidos. O presente trabalho teve por objetivo avaliar o processo de produção de forragem através do estudo de seus componentes; crescimento e senescência. Os tratamentos corresponderam a quatro condições de pasto caracterizadas pelas alturas de 5, 10, 15 e $20 \mathrm{~cm}$, mantidas constante através do pastejo por ovinos em regime de lotação contínua e taxa de lotação variável. O delineamento experimental utilizado foi o de blocos completos casualizados, com quatro repetições. Foram avaliadas as seguintes respostas: alongamento de hastes, alongamento de folhas, senescência, filocrono e o número de folhas por perfilho. Os resultados revelaram um padrão estacional de produção de forragem, com as maiores taxas de crescimento e senescência sendo observadas nas alturas de pasto mais altas (15 e $20 \mathrm{~cm}$ ). O filocrono variou com a época do ano e com a altura de pasto, revelando uma alta associação com variações em temperatura do ar, disponibilidade de água no solo e índice de área foliar do pasto. As alturas de 15 e $20 \mathrm{~cm}$ resultaram na maior produção de matéria seca. Os mesmos princípios e relações originalmente descritos para plantas forrageiras de clima temperado são válidos para plantas tropicais dentro do contexto das limitações fisiológicas e de ambiente inerentes para cada condição.

Palavras-chave: Cynodon, crescimento, senescência, líquido, fluxo de tecidos
\end{abstract}

\section{DRY MATTER ACCUMULATION DYNAMICS IN GRAZED TIFTON 85 BERMUDAGRASS SWARDS}

\begin{abstract}
Herbage dry matter accumulation from forage plants results from the balance between growth and senescence. Agronomic practices may influence both processes in different ways and, therefore, alter the quantitative and qualitative patterns of dry matter production. This study aimed at evaluating the process of dry matter accumulation through measurements of growth and senescence. Experimental treatments corresponded to four sward state conditions $(5,10,15$ and $20 \mathrm{~cm}$ of sward surface height - SSH) generated by sheep grazing under continuous stocking and variable stocking rate. The experimental design was a complete randomised block, with four treatments and four replicates. Pasture responses evaluated were: stem elongation, leaf lamina elongation, senescence, phyllochron and number of leaves per tiller. The results showed a seasonal pattern of herbage production with the highest growth and senescence rates observed at the highest SSH studied $(15$ and $20 \mathrm{~cm}$ ). Phyllochron varied according to time of the year and $\mathrm{SSH}$, revealing an intimate relationship with air temperature variation, soil water availability and sward leaf area index. SSH of 15 and 20 $\mathrm{cm}$ resulted in the highest dry matter production. The same principles and relationships originally described for herbage accumulation in temperate grass pasture species are valid for tropical areas within the framework of the physiological and environmental constraints inherent to each condition.

Key words: Cynodon, tissue flows, growth, net accumulation, senescence
\end{abstract}

\section{INTRODUÇÃO}

Em uma comunidade de plantas forrageiras de uma mesma espécie de gramínea, a unidade vegetativa básica é o perfilho (Hodgson, 1990). Os eventos fenológicos que ocorrem em cada um desses perfilhos assumem um caráter mais abrangente quando observados na população total de plantas, onde qualquer alteração no ambiente pode promover variações na estrutura e características do dossel, que podem, por sua vez, resultar em alterações nos padrões de resposta de produção vegetal e animal. A produção de novos tecidos em um indivíduo é caracterizada pelo crescimento de novas estruturas, como folhas e hastes. No entanto, o crescimento não é o único processo determinante da produção vegetal num ambiente de pastagem. Existem outros processos que ocorrem de forma simultânea, de modo que o acúmulo de forragem é o resultado do balanço líquido entre eles. Assim, a produção de tecidos novos pela planta forrageira (crescimento) ocorre simultaneamente à perda de tecidos velhos por senescência e morte (Hodgson, 1990; Maraschin, 1996), 
equilíbrio este que opera em perfilhos individuais. $O$ conjunto de perfilhos (densidade populacional), associado aos padrões demográficos de perfilhamento (natalidade, mortalidade e sobrevivência), determina a produção da pastagem (Bircham \& Hodgson, 1983). Práticas agronômicas podem influenciar esses dois processos de maneiras distintas e, portanto, modificar os padrões quantitativos e qualitativos da produção de matéria seca.

O crescimento, caracterizado pela emissão de novas estruturas (folhas e/ou hastes), é o principal determinante da produção de matéria seca. Contudo, o processo de senescência atua no mesmo ambiente e de forma antagônica, gerando um efeito compensatório e "homeostático" sobre a produção de forragem (Grant et al., 1988; Hodgson, 1990). Do ponto de vista ecológico, esses mecanismos de compensação atuantes na comunidade podem ser visualizados como 0 aparecimento de novos pontos de crescimento e de atividade fotossintética nas plantas e o retorno de material orgânico em decomposição ao sistema solo:planta.

Os fatores que influenciam as taxas de crescimento e perdas são interrelacionados, até um ponto onde fica difícil separar suas importâncias relativas de forma a manejá-los independentemente um do outro. Em termos práticos, o manejo racional de pastagens corresponde a uma técnica que permita a colheita da máxima quantidade possível de matéria seca verde e assegure uma redução das perdas por senescência, morte e decomposição de tecidos a um mínimo. Este ponto de colheita pode ser determinado para as diferentes espécies e cultivares de plantas forrageiras por meio de estudos de fluxo de tecidos (dinâmica de acúmulo de matéria seca) (Da Silva \& Pedreira, 1997). O ponto de colheita ideal seria aquele onde o acúmulo líquido fosse máximo (Parsons, 1988). O crescimento aumenta durante a rebrota até atingir um patamar a partir do qual não existe vantagem em incremento de produção, pois a quantidade de material senescente pode aumentar muito, levando, em condições extremas, a um acúmulo negativo de matéria seca (Parsons, 1988). Os objetivos deste trabalho foram quantificar as variáveis morfogênicas em perfilhos individuais relacionadas com o acúmulo de matéria seca e estimar as taxas de crescimento, senescência e acúmulo líquido de forragem em pastagens de Tifton- 85 submetidas a pastejo por ovinos sob regime de lotação contínua e taxa de lotação variável.

\section{MATERIAL E MÉTODOS}

O experimento foi realizado na Unidade Experimental de Plantas Forrageiras (UEPF), do Departamento de Produção Animal da Escola Superior de Agricultura "Luiz de Queiroz", Universidade de São Paulo, Piracicaba, São Paulo, localizado a $22^{\circ} 42^{\prime} 30$ " de latitude sul, $47^{\circ} 38^{\prime} 00^{\prime \prime}$ de longitude oeste e $546 \mathrm{~m}$ de altitude (Ometto, 1989). O período experimental foi dividido em quatro épocas de coleta. Cada época foi definida a partir de dados prévios de ensaios realizados com plantas do mesmo gênero (Carnevalli \& Da Silva, 1999), e foram espaçadas ao longo do período experimental de uma maneira que julgou-se abranger mudanças importantes nos padrões de crescimento e senescência. Cada coleta foi subdividida em três datas de amostragem (dia 0 , dia 1, dia 2 ) e realizadas segundo intervalos constantes dentro do mesmo período amostral, porém variáveis em função da época do ano. A primeira avaliação foi de 12/12/98 a 18/12/98; a segunda de 02/ 02/99 a 08/02/99; a terceira de 29/03/99 a 05/04/99 e finalmente a última do dia 03/07/99 a 17/07/99, com intervalos entre datas de amostragem de $3 / 3,3 / 3,3 / 4 \mathrm{e}$ 7/7 dias, respectivamente. Esses intervalos foram dimensionados de forma a procurar assegurar-se um mínimo de dois intervalos de aparecimento de folhas por período de avaliação, utilizando-se como base os dados de Carnevalli \& Da Silva (1999).

\section{Pastagem e período experimental}

As unidades experimentais foram instaladas em solo classificado como Nitossolo Vermelho Eutrófico, com horizonte A moderado de textura argilosa/muito argilosa. A análise do solo realizada no início da implantação da área experimental, revelou um nível de fertilidade bastante elevado (TABELA 1), razão pela qual não foram realizadas práticas de calagem no momento da implantação ou durante o experimento.

As pastagens foram implantadas em março de 1996 por meio de mudas, sendo que, devido às adversidades climáticas e ao baixo percentual de pegamento, fez-se o replantio de algumas parcelas durante os meses de fevereiro e março de 1997. Em 1997 foram fertilizadas com $150 \mathrm{~kg} \mathrm{~N}^{-1}$ na forma de sulfato de amônio. Em 1998 receberam $40 \mathrm{~kg} \mathrm{~N}$ ha-1 $^{-1}$ na forma de sulfato de amônio em janeiro, julho e setembro, $50 \mathrm{~kg}$ $\mathrm{N}$ ha ${ }^{-1}$ em outubro e $25 \mathrm{~kg} \mathrm{~N}^{-1} \mathrm{em}^{-1}$ dezembro. Um corte de uniformização foi realizado em março de 1998 a cerca de $3 \mathrm{~cm}$ do nível do solo. Os animais foram alocados às unidades experimentais à medida que as alturas previstas dos tratamentos eram atingidas (a partir de maio).

O período experimental iniciou-se em 12 de dezembro de 1998 e estendeu-se até 17 de julho de 1999. Nesse ano foram realizadas duas adubações nitrogenadas; a primeira em fevereiro $\left(50 \mathrm{~kg} \mathrm{~N} \mathrm{ha}^{-1}\right)$ e a segunda em março $\left(75 \mathrm{~kg} \mathrm{~N}^{-1}\right)$. As quantidades de fertilizantes aplicadas foram calculadas a fim de que fosse conseguido um acúmulo mínimo de forragem suficiente para manter pelo menos dois animais por unidade experimental durante todo o período de avaliação.

\section{Condições climáticas}

Conforme o sistema Köppen, o clima da região de Piracicaba é classificado como Cwa, isto é, mesotérmico úmido, subtropical de inverno seco, onde 
a temperatura do mês mais frio é inferior a $18^{\circ} \mathrm{C}$ e a do mês mais quente ultrapassa os $22^{\circ} \mathrm{C}$ (Brasil, 1960). Os dados climáticos referentes ao período experimental encontram-se na TABELA 2.

\section{Delineamento e manutenção das condições experimentais}

O delineamento experimental utilizado foi o de blocos completos casualizados com quatro repetições. O cultivar Tifton-85 foi submetido a quatro condições de pasto (alturas de 5, 10, 15 e $20 \mathrm{~cm}$ ), mantidas em situação de equilíbrio. Cada parcela possuía cerca de $400 \mathrm{~m}^{2}$ e o controle das alturas foi realizado através de pastejo por ovinos em regime de lotação contínua e taxa de lotação variável. A altura média dos pastos foi monitorada semanalmente através da tomada de 20 leituras em cada unidade experimental com o prato ascendente, duas vezes por semana. Uma vez ao mês era feita a calibração entre a altura comprimida do pasto e a altura não comprimida (régua), gerando-se, dessa forma, o valor de altura utilizado como referência para o monitoramento dos tratamentos. Os animais foram adicionados ou retirados das unidades experimentais quando os pastos estavam acima ou abaixo da altura predeterminada, respectivamente.

\section{Avaliações de campo}

A dinâmica de fluxo de tecidos foi avaliada em cada unidade experimental em duas transectas lineares de dois metros demarcadas por duas estacas colocadas em regiões representativas da condição do pasto. Nessa régua, foram marcados 10 pontos espaçados de 0,2 m. Cada ponto correspondia a um perfilho marcado por anéis plásticos coloridos (2 a $5 \mathrm{~mm}$ de diâmetro, e 3 a

TABELA 1 - Análise química do solo da área experimental antes do início do experimento.

\begin{tabular}{|c|c|c|c|c|c|c|c|c|c|}
\hline $\begin{array}{c}\mathrm{pH} \\
\mathrm{CaCl}_{2}\end{array}$ & M.O. & $\mathrm{P}$ & K & $\mathrm{Ca}$ & $\mathrm{Mg}$ & $\mathrm{H}+\mathrm{Al}$ & SB & T & V \\
\hline & $\mathrm{g} \mathrm{dm}^{-3}$ & $\mathrm{mg} \mathrm{dm}^{-3}$ & -------- & ----- & --- & ol & 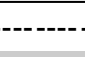 & ------ & $\%$ \\
\hline 5,4 & 37,0 & 99 & 4,6 & 75 & 26 & 30 & 106 & 136 & 78,0 \\
\hline
\end{tabular}

TABELA 2 - Temperaturas médias mensais do ar (máxima média, mínima média e média), precipitação pluvial e insolação diária média durante o período experimental (de novembro/98 a julho/99) e comparação com os dados dos últimos 80 anos.

\begin{tabular}{|c|c|c|c|c|c|}
\hline \multirow{2}{*}{ Mês/ano } & \multicolumn{3}{|c|}{ Temperatura $\left({ }^{\circ} \mathrm{C}\right)$} & \multirow{2}{*}{ Precipitação } & \multirow{2}{*}{ Insolação média* } \\
\hline & Máxima média & Mínima média & Média & & \\
\hline & & & & $\mathrm{mm}$ chuva & $\mathrm{hdia}^{-1}$ \\
\hline Outubro/98 & 27,1 & 16,3 & 21,7 & 183,1 & 5,4 \\
\hline Média (80 anos - outubro) & 28,9 & 15,6 & 22,2 & 111,3 & 6,9 \\
\hline Novembro/98 & 30,0 & 16,4 & 23,2 & 26,6 & 7,8 \\
\hline Média (80 anos- novembro) & 29,6 & 16,7 & 23,1 & 130,0 & 7,4 \\
\hline Dezembro/98 & 30,0 & 19,2 & 24,6 & 292,6 & 6,1 \\
\hline Média (80 anos- dezembro) & 29,6 & 18,1 & 23,9 & 200,2 & 6,6 \\
\hline Janeiro/99 & 31,4 & 19,0 & 25,2 & 210,8 & 7,7 \\
\hline Média (80 anos - janeiro) & 30,0 & 18,2 & 24,0 & 142,4 & 6,8 \\
\hline Fevereiro/99 & 30,7 & 20,0 & 25,4 & 198,3 & 5,4 \\
\hline Média (80 anos - fevereiro) & 30,2 & 19,0 & 24,6 & 185,9 & 6,5 \\
\hline Março/99 & 31,4 & 19,0 & 25,2 & 210,8 & 7,7 \\
\hline Média (80 anos - março) & 30,0 & 18,2 & 24,0 & 142,4 & 6,9 \\
\hline Abril/99 & 28,5 & 15,2 & 21,9 & 89,0 & 8,1 \\
\hline Média (80 anos - abril) & 28,3 & 15,4 & 21,8 & 64,8 & 7,5 \\
\hline Maio/99 & 25,4 & 11,2 & 18,3 & 51,3 & 7,4 \\
\hline Média (80 anos - maio) & 26,1 & 12,1 & 19,1 & 52,7 & 7,2 \\
\hline Junho/99 & 23,9 & 11,0 & 17,4 & 68,6 & 6,0 \\
\hline Média (80 anos - junho) & 24,9 & 10,3 & 17,6 & 44,5 & 7,1 \\
\hline Julho/99 & 26,4 & 12,0 & 19,2 & 2,7 & 6,7 \\
\hline Média (80 anos - julho) & 25,3 & 9,5 & 17,4 & 26,8 & 7,8 \\
\hline
\end{tabular}

*Dados históricos de 77 anos

Fonte: Arquivos do Departamento de Ciências Exatas - USP/ESALQ (1999) 
$5 \mathrm{~mm}$ de comprimento), identificado por meio de coordenadas de ângulo e distância em relação à régua para facilidade de localização. Um novo grupo de perfilhos era escolhido a cada época de avaliação.

A escolha de perfilhos para marcação foi feita procurando-se evitar plantas debilitadas ou injuriadas por qualquer razão. A cada época de avaliação eram contadas todas as folhas cujo comprimento era medido com régua, sendo o aparecimento de novas folhas determinado e registrado (aparecimento = visualização da lâmina emergente). Nas folhas senescentes mediuse o comprimento da lâmina foliar verde, da lígula até a "linha limítrofe" com a porção senescida (amarelada/ parda). As folhas adultas (com lígula exposta) e emergentes foram ainda subdivididas nas categorias "intacta" e "pastejada". Nas folhas emergentes o comprimento da lâmina foliar era medido da ponta da folha até a lígula da última folha totalmente expandida. Durante o processo de marcação as folhas foram identificadas por números, sendo o número 1 destinado à folha mais velha, basal, e os demais seqüencialmente subindo-se na axis do perfilho. Os dados originalmente obtidos foram todos em unidade de comprimento $(\mathrm{mm})$.

\section{Processamento dos dados}

Com a finalidade de permitir a expressão dos valores das taxas de alongamento de folhas, alongamento de hastes, crescimento e senescência em $\mathrm{kg} \mathrm{MS/ha} \mathrm{foi} \mathrm{necessário} \mathrm{a} \mathrm{geração} \mathrm{de} \mathrm{um} \mathrm{fator} \mathrm{de}$ conversão. No dia 2 de cada coleta (terceira medição consecutiva), todos os perfilhos marcados foram cortados no nível do solo, colocados em sacolas de plástico umedecidas e levados a uma caixa de isopor com gelo para reduzir a desidratação e respiração dos perfilhos. Após medição de todos os componentes de haste e folhas, conforme realizado no campo nas datas 0 e 1 de cada avaliação, todas as lâminas foliares de cada perfilho foram destacadas junto à lígula correspondente e as porções resultantes agrupadas em folhas emergentes, totalmente expandidas e senescentes, intactas ou pastejadas, e hastes. Cada um desses componentes foi levado então para estufa a $65^{\circ} \mathrm{C}$ por 48 horas. Após secagem, o material foi pesado e o peso de cada componente dividido pelo comprimento total correspondente na régua. Foi obtido assim um fator de conversão $\left(\mathrm{mg} \mathrm{mm}^{-1}\right)$ utilizado para transformar todas as leituras de campo, expressas em mm/perfilho.dia, em mg/ perfilho.dia. A transformação final para kg MS ha- $\mathrm{dia}^{-1}$ foi realizada através da multiplicação desses valores pela densidade populacional média de perfilhos em cada unidade experimental. A densidade populacional de perfilhos foi determinada através do quociente entre massa de forragem e peso médio por perfilho em trabalho realizado na mesma área por Sbrissia (2000).

\section{Cálculo das variáveis experimentais}

As variáveis estudadas foram taxa de aparecimento e expansão de folhas "intactas" e "pastejadas", taxa de alongamento de haste, filocrono (dias/folha e graus-dia/folha), taxa de crescimento, taxa de senescência, taxa de acúmulo líquido.

Para o cálculo da taxa de aparecimento de folhas (TAF) foi utilizado o número médio de folhas que apareceu em cada perfilho do dia 0 ao dia 2 em cada régua. Esse valor, dividido pelo número total de dias do período, resultou na TAF expressa em folhas/perfilho.dia.

Para o cálculo do filocrono em dias/folha, utilizouse 0 inverso da TAF (1/TAF), conforme descrito por Lemaire \& Chapmam (1996). O filocrono expresso com base em graus-dia (GD) por folha teve o valor de GD calculado como sendo o somatório das diferenças entre a temperatura média diária e a temperatura basal assumida de $15^{\circ} \mathrm{C}$ durante cada época de avaliação. $\mathrm{O}$ valor obtido foi dividido pelo número de folhas surgidas durante o mesmo período. Os dados de temperatura utilizados foram coletados no Posto Meteorológico do Departamento de Ciências Exatas da ESALQ/USP. O valor de temperatura basal escolhido baseou-se no fato de que plantas do gênero Cynodon praticamente cessam o seu crescimento em temperaturas inferiores a $15^{\circ} \mathrm{C}$ (Youngner, 1972).

As variações em comprimento de cada folha $e$ haste, em cada data de amostragem, possibilitou o cálculo das taxas de crescimento e senescência. Variações positivas em comprimento possibilitaram o cálculo das taxas de crescimento $\left(\mathrm{mm} \mathrm{dia}^{-1}\right)$, tanto para folhas como para hastes, intactas ou pastejadas. No caso de diminuição da parte verde do limbo foliar (variações negativas em comprimento), ou seja, aumento na porção amarelada/parda das folhas, foi possível 0 acompanhamento das taxas de senescência de forma análoga ao crescimento. A diferença entre essas duas variáveis (crescimento e senescência) possibilitou a estimativa das taxas de acúmulo de matéria seca.

\section{Análise estatística}

Os dados foram analisados utilizando-se 0 procedimento GLM (General Linear Models) do pacote estatístico do SAS (Statistical Analysis System). Dentro desse procedimento, optou-se pelo sub-procedimento de medidas repetidas no tempo (Repeated Measures) (SAS Institute, 1988). Dessa forma foi possível detectar-se os efeitos de altura, épocas de coleta e interações época de coleta $x$ altura. Todos os conjuntos de dados foram testados, antes da análise geral global, para normalidade dos dados e homogeneidade das variâncias. Utilizou-se - "LSMEANS" para comparação de médias entre tratamentos e assumiu-se um nível de significância de $10 \%$.

\section{RESULTADOS E DISCUSSÃO}

As características morfogênicas do relvado são responsáveis pelas variações que ocorrem na estrutura da pastagem (Lemaire \& Chapmam, 1996). Uma delas é a taxa de aparecimento de folhas (TAF), cujo inverso 
estima o filocrono (dias/folha, DF), que variou em função do mês de avaliação ( $P=0,0004)$ (TABELA 3).

Houve um aumento nos valores de DF ao longo das avaliações. Esse aumento, provavelmente, foi conseqüência da variação nas condições de ambiente, especialmente insolação (TABELA 2). O filocrono pareceu estar fortemente relacionado com o índice de área foliar do relvado (IAF). Os dados de Sbrissia (2000), coletados concomitantemente na mesma área experimental, mostraram que também houve um incremento no IAF durante o período de avaliação. Foram verificadas diferenças entre as alturas do relvado em todos os meses de avaliação, exceto o mês de abril/ 99. Os menores valores de filocrono no mês de fevereiro/99 para pastos de $5 \mathrm{~cm}$ podem ser explicados pelo menor valor de IAF (Sbrissia, 2000). Contudo, a diferença em IAF entre as alturas de 10 e $15 \mathrm{~cm}$ foi muito pequena para poder explicar o menor valor de filocrono para a altura de $15 \mathrm{~cm}$. Por outro lado, esse comportamento pode ter estado associado a outras características do relvado, como o tamanho das folhas. Como não houve diferenças entre o número de folhas vivas por perfilho, a manutenção do IAF pode ter sido obtida por meio de um aumento na população de perfilhos, suficiente para compensar a redução no tamanho das folhas. Já em dezembro/98, foi observada uma tendência inversa, onde as maiores alturas de relvado apresentaram menores valores de filocrono. Esse fato pode estar relacionado com o período de déficit hídrico no mês de novembro/98, o qual acabou prejudicando, principalmente, as menores alturas de pasto. Houve, portanto, uma redução no perfilhamento (Carvalho, 2000), redução no IAF (Sbrissia, 2000) e, consequentemente, maiores valores de filocrono. Para os outros meses de avaliação o comportamento voltou a ser normal, ou seja, quanto menor a altura de pasto, menor o filocrono. Dessa forma, folhas menores necessitariam de um menor número de dias para completarem seu desenvolvimento. Os valores de filocrono encontrados no presente estudo são próximos daqueles apresentados para Coastcross por Carnevalli \& Da Silva (1999), que variaram de 3,0 a 5,8 dias/folha ao longo dos 9 meses do período de avaliação.

O filocrono também pode ser expresso em função de soma térmica, ou seja, a quantidade de grausdia necessária para a formação de uma folha (TABELA 3). Para essa variável foi observado efeito de mês de avaliação $(P=0,0008)$ e comportamento semelhante ao observado para DF, exceto em julho/99, onde houve uma grande redução dos valores de GD. Esse comportamento pode estar relacionado com o menor tamanho das folhas e com o florescimento do pasto observados a partir de abril/99. A soma térmica acumulada durante esse mês foi muito pequena, o que resultou em uma maior taxa de aparecimento de folhas (folhas/dia). Já a primeira avaliação, apresentou valores menores de GD. Uma possível explicação para esse comportamento seria o déficit hídrico ocorrido em novembro/98 (TABELA 2). Segundo Morales et al. (1997), a diminuição da disponibilidade de água no solo leva a uma redução da emissão de novas ramificações, do tamanho médio dos folíolos e uma redução na emissão de folhas novas nas hastes já formadas. Essa estratégia de sobrevivência da planta pode levar a uma limitação da capacidade de competição por luz, levando a uma diminuição da área foliar e, portanto, um incremento nos valores de GD (Morales et al., 1997). Os resultados obtidos neste estudo foram semelhantes àqueles observados por Oliveira et al. (1998), que utilizando uma temperatura basal de $10^{\circ} \mathrm{C}$ para Tifton-85 obtiveram valores de 25 a $46 \mathrm{GD} /$ folha. Como todos os fatores de ambiente modificam-se ao longo do ano, variações nos valores de filocrono e taxa de aparecimento de folhas devem ser esperadas (Carnevalli \& Da Silva, 1999).

Com relação à taxa de alongamento de hastes (TH), foi observada interação entre mês de avaliação $x$

TABELA 3 - Valores de filocrono em 'dias/folha' e 'em graus-dia/folha' calculados para as diferentes alturas de pasto estudadas.

\begin{tabular}{|c|c|c|c|c|c|c|c|}
\hline \multirow{2}{*}{\multicolumn{2}{|c|}{ Época de avaliação ${ }^{1}$}} & \multicolumn{4}{|c|}{ Altura do pasto } & \multirow{2}{*}{ Média } & \multirow{2}{*}{$\mathrm{EPM}^{*}$} \\
\hline & & 5 & 10 & 15 & 20 & & \\
\hline \multirow{5}{*}{$\mathrm{DF}^{2}$} & & n & - & m - - - - - & - n n & & \\
\hline & 1 & $4,1 \mathrm{ab}$ & $4,3 \mathrm{a}$ & $4,0 a b$ & $3,1 \mathrm{~b}$ & 3,9 & 0,44 \\
\hline & 2 & $3,8 b$ & $4,9 a$ & $4,2 \mathrm{~b}$ & $5,3 a$ & 4,5 & 0,22 \\
\hline & 3 & $4,7 \mathrm{a}$ & $4,8 \mathrm{a}$ & $5,3 a$ & $5,4 a$ & 5,0 & 0,35 \\
\hline & 4 & $8,3 \mathrm{a}$ & $9,2 a b$ & $8,5 \mathrm{ab}$ & $11,4 \mathrm{~b}$ & 9,3 & 1,14 \\
\hline \multirow{4}{*}{$\mathrm{GD}^{3}$} & 1 & $51,3 \mathrm{ab}$ & $53,2 \mathrm{a}$ & $50,5 a b$ & $39,0 \mathrm{~b}$ & 48,5 & 5,44 \\
\hline & 2 & $48,7 \mathrm{~b}$ & $63,4 \mathrm{a}$ & $53,7 \mathrm{~b}$ & $67,9 \mathrm{a}$ & 58,4 & 2,88 \\
\hline & 3 & $60,2 \mathrm{a}$ & $60,5 \mathrm{a}$ & $66,7 \mathrm{a}$ & $68,9 a$ & 64,1 & 4,39 \\
\hline & 4 & $33,6 \mathrm{~b}$ & $37,1 \mathrm{ab}$ & $34,3 a b$ & $45,8 a$ & 37,7 & 4,59 \\
\hline
\end{tabular}

*EPM - Erro padrão da média. Letras iguais na mesma linha não diferem a $(P>0,10)$.

${ }^{1}$ Data 1=Dezembro/98, Data 2=Fevereiro/99, Data 3=Abril/99 e Data 4=Julho/99.

${ }^{2} \mathrm{DF}=$ folhas $\mathrm{dia}^{-1}$

${ }^{3} \mathrm{GD}=$ graus dia folha ${ }^{-1}$ 
altura de relvado $(P=0,0974)$. Os dados mostraram que houve um aumento das $\mathrm{TH}$ ao longo dos meses, principalmente para as maiores alturas de pasto (15 e $20 \mathrm{~cm}$ ) a partir de abril/99 até julho/99 (TABELA 4). Esse fato pode ter estado relacionado com o início do processo de florescimento nas plantas que, nessa condição, seria beneficiado pelas alturas de relvado mais elevadas (menor intensidade de pastejo).

Para a taxa de expansão de folhas intactas (TI) foi observado efeito de época de avaliação ( $P=0,0098)$. Houve também diferenças entre as alturas de relvado estudadas, exceto em dezembro/98. Foi observada uma redução das $\mathrm{Tl}$ ao longo dos meses do ano. No final da primavera (dezembro) e meio do verão (fevereiro) as TI foram consideravelmente maiores que aquelas observadas no final do outono (abril) e início do inverno (julho). A diminuição da TI nos meses de abril e julho pode ter sido conseqüência da diminuição da disponibilidade de fatores de ambiente determinantes do crescimento, principalmente luminosidade (Parsons et al., 1983) e temperatura (Lemaire \& Agnusdei, 1999) (TABELA 2). A taxa de expansão de folhas é um processo dependente de fatores de ambiente como temperatura, água, luz, nitrogênio etc., principalmente luminosidade (Lemaire \& Chapmam, 1996; Lemaire \& Agnusdei, 1999). Assim, a taxa de expansão de folhas, que acaba por determinar o seu tamanho final, apresenta grande influência sobre o IAF do pasto (Lemaire \& Agnusdei, 1999).

Com relação a taxa de expansão de folhas pastejadas (TD), foi observado efeito de mês de avaliação $(P=0,0269)$. A diminuição das TD ao longo dos meses indica que as folhas pastejadas seguiram o mesmo padrão de resposta apresentado pelas folhas intactas com relação aos fatores de ambiente. Contudo, os valores de TD corresponderam, em média, a apenas 19\% dos valores observados para TI. Um motivo para essa discrepância pode estar relacionado com a quantidade de tecido fotossintéticamente ativo de um tipo de folha para outro. As folhas pastejadas interceptam menos luz e, consequentemente, contribuem menos para a produção de biomassa do pasto. Outro aspecto importante é o fato de que a porção foliar remanescente após o pastejo apresenta uma menor capacidade de expansão celular em relação à parte inicial da folha retirada pelo animal. Assim, a taxa de expansão de uma folha apresenta-se inicialmente acelerada, reduzindo-se, progressivamente, após a exteriorização do primeiro terço foliar (Pinto et al., 1994). Esse diferencial em taxas de expansão entre folhas pastejadas e intactas foi também relatado por Bircham \& Hodgson (1983) para azevém perene. A soma de TI e TD define a contribuição em termos de $\mathrm{kg} \mathrm{MS} / \mathrm{ha}$.dia proveniente somente de folhas. Assim, os valores ficaram por volta de $38 \mathrm{~kg} \mathrm{MS} \mathrm{ha}^{-1} \mathrm{dia}^{-1}$.

Com relação às taxas de crescimento do relvado (TC), foi observado um aumento dos valores ao longo das épocas de avaliação (TABELA 5).
$\mathrm{O}$ aumento nas TC ocorre basicamente de duas maneiras: aumento no peso individual dos perfilhos e/ ou aumento no número de perfilhos. Sbrissia (2000) mostrou que o principal determinante do aumento em biomassa do relvado a partir de abril/99 foi o aumento no número de perfilhos. Contudo, esses perfilhos eram muito pequenos e de curta longevidade ("rosetas"). A média dos valores encontrados neste estudo (142 kg MS $\mathrm{ha}^{-1} \mathrm{dia}^{-1}$ ) é semelhante àquela encontrada para outras espécies de plantas forrageiras tropicais. Gomide et al. (1997), trabalhando com Brachiaria decumbens, obtiveram valores de $154 \mathrm{~kg} \mathrm{MS} \mathrm{ha-1} \mathrm{dia}^{-1}$ para uma disponibilidade de forragem de $4.400 \mathrm{~kg} \mathrm{ha}^{-1} \mathrm{de}$ biomassa. Almeida et al. (1997), trabalhando com capim elefante anão, obtiveram 59,0, 93,6, 149,2 e 159,4 kg MS $\mathrm{ha}^{-1} \mathrm{dia}^{-1}$ para ofertas de forragem de 3,8, 7,5, 10,5 e 14,7 $\mathrm{kg}$ MS de lâmina verde/100 kg de peso vivo, respectivamente.

Apesar dos relvados mantidos mais altos (15 e $20 \mathrm{~cm}$ ) terem apresentado os maiores valores de crescimento, exceto para a altura de $20 \mathrm{~cm}$ no mês de abril/99, uma maior proporção da forragem produzida foi destinada para a manutenção da altura de pastejo e, consequentemente, com maiores perdas pelos processos de senescência e morte, enquanto que nos pastos mantidos mais baixos (maiores taxas de lotação) menor foi a proporção de tecido senescente, já que ambos os processos (crescimento e senescência) são antagônicos e o diferencial positivo ou negativo entre eles é determinado pelas características de estrutura do pasto (Hodgson, 1990). Para taxa de senescência (TS) foi observado efeito de época de avaliação $(P=0,0191)$. Houve um aumento nos valores de TS ao longo dos meses de avaliação. Na quarta avaliação, houve um comportamento semelhante entre as alturas de 5 e 10 $\mathrm{cm}$, mas que diferiram estatisticamente das alturas de 15 e $20 \mathrm{~cm}$. Pastos mantidos a $5 \mathrm{~cm}$ apresentaram valores praticamente constantes de TS, por volta de 18,0 $\mathrm{kg} \mathrm{MS} \mathrm{ha-1} \mathrm{dia}^{-1}$. Já aqueles mantidos a $10 \mathrm{~cm}$ mostraram valores ligeiramente superiores àqueles da altura de 5 $\mathrm{cm}$, com um valor médio de $24,0 \mathrm{~kg} \mathrm{MS} \mathrm{ha}^{-1} \mathrm{dia}^{-1}$. Os pastos mantidos a $15 \mathrm{~cm}$ apresentaram um grande incremento nas TS da segunda para a terceira época de avaliação (20,1 para $\left.68,0 \mathrm{~kg} \mathrm{MS} \mathrm{ha}^{-1} \mathrm{dia}^{-1}\right)$. Assim, as maiores variações em TS foram observadas para as maiores alturas de pasto. Os dados de crescimento do pasto mostraram que o Tifton-85 apresentou um grande incremento nas TC de abril para julho/99. Consequentemente, os valores das TS aumentaram, mostrando novamente a relação direta entre esses dois processos dinâmicos e concomitantes em comunidades de plantas. No entanto, vale observar que os valores de TC e TS para o mês de julho/99 foram muito elevados em relação ao que seria esperado para aquela época do ano. Dois podem ter sido os fatores responsáveis por isso: (1) densidades populacionais de perfilhos anormalmente elevadas em função da ocorrência de 
TABELA 4 - Taxa $\left(\mathrm{kg} \mathrm{ha}^{-1}\right.$ dia $\left.^{-1}\right)$ de crescimento de haste (TH), de folhas intactas (TI) e pastejadas (TD) para as alturas de relevado estudadas

\begin{tabular}{|c|c|c|c|c|c|c|c|}
\hline \multirow{2}{*}{\multicolumn{2}{|c|}{ Época de avaliação ${ }^{1}$}} & \multicolumn{4}{|c|}{ Altura do pasto } & \multirow{2}{*}{ Média } & \multirow{2}{*}{$\mathrm{EPM}^{*}$} \\
\hline & & 5 & \multirow[t]{2}{*}{10} & \multirow{2}{*}{$\begin{array}{c}15 \\
\end{array}$} & 20 & & \\
\hline & & - & & & - & & \\
\hline \multirow{4}{*}{$\mathrm{TH}$} & 1 & $45,8 \mathrm{a}$ & $100,2 \mathrm{a}$ & 89,3 a & $100,8 \mathrm{a}$ & 84,0 & 25,0 \\
\hline & 2 & $31,2 \mathrm{~b}$ & $79,2 a b$ & 110,6 a & 114,9 a & 84,0 & 28,9 \\
\hline & 3 & $30,0 \mathrm{~b}$ & $59,1 \mathrm{~b}$ & 235,8 a & $96,9 \mathrm{~b}$ & 105,5 & 25,8 \\
\hline & 4 & $79,6 \mathrm{~b}$ & $66,4 \mathrm{~b}$ & $172,6 \mathrm{ab}$ & 245,8 a & 141,1 & 53,6 \\
\hline \multirow{4}{*}{$\mathrm{TI}$} & 1 & $22,4 a$ & $26,0 \mathrm{a}$ & 27,3 a & 42,2 a & 29,5 & 10,81 \\
\hline & 2 & $38,3 \mathrm{~b}$ & $58,8 \mathrm{a}$ & $33,8 \mathrm{~b}$ & $44,4 a b$ & 43,8 & 6,08 \\
\hline & 3 & $17,6 \mathrm{~b}$ & $46,6 \mathrm{a}$ & $28,9 a b$ & $39,1 \mathrm{ab}$ & 33,0 & 9,89 \\
\hline & 4 & $24,6 a b$ & $9,3 \mathrm{~b}$ & 35,9 a & $18,1 \mathrm{ab}$ & 22,0 & 8,61 \\
\hline \multirow{4}{*}{ TD } & 1 & 18,9 a & $3,1 \mathrm{~b}$ & $4,2 \mathrm{~b}$ & $12,3 \mathrm{ab}$ & 9,6 & 4,96 \\
\hline & 2 & $0,11 \mathrm{~b}$ & $12,3 \mathrm{a}$ & $0,14 \mathrm{~b}$ & $2,0 a b$ & 3,6 & 4,11 \\
\hline & 3 & $8,1 a b$ & $14,0 \mathrm{a}$ & $10,2 a b$ & $1,5 \mathrm{~b}$ & 8,5 & 4,05 \\
\hline & 4 & $2,9 \mathrm{~b}$ & $2,6 b$ & $6,1 \mathrm{a}$ & $0,13 c$ & 2,9 & 0,89 \\
\hline
\end{tabular}

*EPM - Erro padrão da média. Letras iguais na mesma linha não diferem a $(P>0,10)$.

'Data 1=Dezembro/98, Data 2=Fevereiro/99, Data 3=Abril/99 e Data 4=Julho/99.

TABELA 5. Taxas de crescimento, senescência e acúmulo de forragem para as diferentes alturas de pasto estudadas.

\begin{tabular}{|c|c|c|c|c|c|c|c|}
\hline \multirow{2}{*}{\multicolumn{2}{|c|}{ Época de avaliação ${ }^{1}$}} & \multicolumn{4}{|c|}{ Altura do pasto } & \multirow{2}{*}{ Média } & \multirow{2}{*}{$\mathrm{EPM}^{*}$} \\
\hline & & \multirow{2}{*}{5} & \multirow{2}{*}{10} & \multirow{2}{*}{ 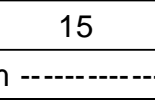 } & \multirow{2}{*}{20} & & \\
\hline & & & & & & & \\
\hline \multirow{4}{*}{$\mathrm{TC}^{2}$} & 1 & $87,1 \mathrm{a}$ & $129,3 \mathrm{a}$ & $120,8 \mathrm{a}$ & $155,2 \mathrm{a}$ & 123,1 & 36,9 \\
\hline & 2 & $69,5 b$ & $150,3 \mathrm{ab}$ & $144,5 a b$ & $161,3 \mathrm{a}$ & 131,4 & 31,6 \\
\hline & 3 & $55,7 \mathrm{c}$ & $119,7 \mathrm{~b}$ & $274,9 \mathrm{a}$ & $137,5 \mathrm{~b}$ & 146,9 & 28,1 \\
\hline & 4 & $107,1 \mathrm{ab}$ & $78,3 \mathrm{~b}$ & $214,7 a b$ & $264,0 \mathrm{a}$ & 166,0 & 60,6 \\
\hline \multirow{4}{*}{$\mathrm{TS}^{3}$} & 1 & $24,5 \mathrm{a}$ & $20,1 a b$ & $18,7 a b$ & $8,8 \mathrm{~b}$ & 18,0 & 5,0 \\
\hline & 2 & $19,9 a$ & $35,2 \mathrm{a}$ & $20,1 \mathrm{a}$ & $20,3 a$ & 23,9 & 8,1 \\
\hline & 3 & $7,5 \mathrm{~b}$ & $23,2 b$ & $68,0 \mathrm{a}$ & $47,0 a b$ & 36,4 & 16,8 \\
\hline & 4 & $29,7 b$ & $15,0 \mathrm{~b}$ & $155,0 \mathrm{a}$ & $141,4 \mathrm{a}$ & 85,3 & 33,0 \\
\hline \multirow{4}{*}{$\mathrm{TA}^{4}$} & 1 & $62,6 a$ & $109,2 \mathrm{a}$ & $102,1 \mathrm{a}$ & $146,4 \mathrm{a}$ & 105,0 & 37,5 \\
\hline & 2 & $49,6 b$ & $115,1 \mathrm{ab}$ & $124,4 a b$ & $141,1 \mathrm{a}$ & 107,5 & 30,0 \\
\hline & 3 & $48,1 \mathrm{~b}$ & $96,4 \mathrm{~b}$ & 206,9 a & $90,5 \mathrm{~b}$ & 110,5 & 25,9 \\
\hline & 4 & $77,4 \mathrm{a}$ & $63,4 \mathrm{a}$ & $59,6 \mathrm{a}$ & $122,7 \mathrm{a}$ & 80,8 & 36,1 \\
\hline
\end{tabular}

*EPM - Erro padrão da média. Letras iguais na mesma linha não diferem a $(P>0,10)$.

${ }^{1}$ Data 1=Dezembro/98, Data 2=Fevereiro/99, Data 3=Abril/99 e Data 4=Julho/99.

${ }^{2} \mathrm{TC}=$ Taxa de crescimento $\left(\mathrm{kg} \mathrm{MS} \mathrm{ha-1} \mathrm{dia}^{-1}\right)$

${ }^{3} \mathrm{TS}=$ Taxa de senescência $\left(\mathrm{kg} \mathrm{MS} \mathrm{ha-1} \mathrm{dia}^{-1}\right)$

${ }^{4} \mathrm{TA}=$ Taxa de acúmulo $\left(\mathrm{kg} \mathrm{MS} \mathrm{ha-1} \mathrm{dia}^{-1}\right)$

rosetas no pasto e (2) limitação do processo de seleção de perfilhos para avaliação, uma vez que foram selecionados perfilhos vigorosos e não constituintes das rosetas. Esses dois fatores em conjunto poderiam explicar as super estimativas observadas naquela época do ano. Contudo, durante as avaliações 1 e 2, foi observado um padrão de senescência inverso àquele descrito por Bircham \& Hodgson (1983), segundo o qual pastos mantidos mais altos apresentam maiores TS. Esse mesmo efeito foi observado por Binnie \& Chesnutt (1994) para trevo branco (Trifolium repens L.) em pastagens consorciadas de trevo branco e azevém. $O$ período de déficit hídrico observado em novembro/98 (TABELA 2) pode ter contribuído ainda mais para um aumento nas TS na menor altura de pasto $(5 \mathrm{~cm})$ em dezembro/98. Para os pastos mantidos mais baixos e que consequentemente apresentaram as maiores densidades populacionais de perfilhos pequenos (Carvalho, 2000), um período de restrição de água deve ter levado a uma maior senescência e morte desses perfilhos em função de uma maior drasticidade relativa da falta de água sob aquelas condições. Assim, o 
equilíbrio entre os processos de crescimento e senescência para aquele mês de avaliação pode ter sido determinado pela disponibilidade de água, indicando uma natureza dinâmica do processo de acúmulo e uma variação do equilíbrio normalmente esperado quando o fator restritivo passa a ser a água e não a luz. Para Grant et al. (1988), as maiores diferenças em termos de TS foram observadas em períodos de seca, e ressaltaram que isso não deveria ser confundido com aspectos de manejo. A partir de fevereiro/99, época em que não foram observadas diferenças entre as alturas de pasto, o padrão de senescência voltou a ser condizente com aquele descrito por Bircham \& Hodgson (1983), Hodgson (1990) e Lemaire \& Chapmam (1996), já que o fator regulador voltou a ser a luz e não mais a água. Os incrementos observados para as TC em abril/99 (TABELA 5) seguiriam os incrementos em TS, principalmente para a altura de $15 \mathrm{~cm}$. Assim, a partir da terceira para a quarta época de avaliação, as maiores alturas de pasto foram as que apresentaram as maiores TS.

O aumento no acúmulo de forragem, determinado pela diferença entre os processos de crescimento e de senescência (Hodgson, 1990), pode resultar em um aumento nos níveis de alimentação e de produção animal (Da Silva, 1994). Foi observada redução das taxas de acúmulo de forragem (TA) ao longo das épocas de avaliação. Isso foi relacionado com o incremento das TS, proporcionalmente maior que o aumento observado em TC. Houve pouca variação em TA ao longo das avaliações, exceto para o mês de julho/ 99, quando foi observada uma grande redução dos valores de TA. Essas variações em TA com o tempo indicam que as taxas de lotação devem variar ao longo do ano, de tal forma que o equilíbrio entre oferta e demanda de forragem seja atingido sem prejudicar 0 desempenho dos animais (Da Silva \& Pedreira, 1997). Outro aspecto importante é a tendência de aumento das TA com o aumento das alturas de pasto. Esses valores observados foram inferiores aos 119 e $216 \mathrm{~kg} \mathrm{MS} / \mathrm{ha}$.dia para uma biomassa de 4.400 e $6.300 \mathrm{~kg} \mathrm{MS} \mathrm{ha}^{-1}$ obtidos por Gomide et al. (1997) . Já plantas de clima temperado apresentam o mesmo padrão de resposta, porém com menores valores absolutos. Hepp et al. (1996), trabalhando com azevém perene, obtiveram valores de TA de 50,6, 24,4 e 21,2 $\mathrm{kg} \mathrm{MS} \mathrm{ha}^{-1}$.dia para os meses de agosto, setembro e outubro, respectivamente. Valores muito próximos a esses foram obtidos em outros estudos com essa mesma planta forrageira (Lolium perenne) variando de 40 a $50 \mathrm{~kg} \mathrm{MS} \mathrm{ha}^{-1} \mathrm{dia}^{-1}$ (Grant et al., 1988), 55,3 a $62,7 \mathrm{~kg} \mathrm{MS} \mathrm{ha}^{-1} \mathrm{dia}^{-1}$ (Binnie \& Chesnutt, 1994) e de 23,9 a 56,2 $\mathrm{kg} \mathrm{MS} \mathrm{ha}^{-1}$ dia $^{-1}$ (Xia et al., 1994). Uma outra característica importante do conjunto de dados deste estudo é a contribuição relativa do crescimento proveniente das hastes $(67,2 \%$ em média), particularmente em épocas próximas ao final da estação de crescimento, indicando que uma porção representativa do potencial de produção de gramíneas tropicais é função da produção de tecidos de hastes. Dessa forma, estudos relacionados com o valor nutritivo de hastes poderiam melhorar o valor alimentar (qualidade) de pastos tropicais sem reduzir o seu potencial produtivo.

\section{CONCLUSÕES}

As alturas de pasto que permitiram as maiores taxas de acúmulo de forragem ficaram entre $15 \mathrm{e}$ $20 \mathrm{~cm}$.

O componente haste do pasto contribui significativamente para a produção de forragem e precisa ser melhor estudado com relação a suas características qualitativas para fins de produção animal.

O equilíbrio clássico descrito para crescimento e senescência sofre alterações significativas quando o fator limitante para o desenvolvimento das plantas passa a ser a água e não a luz, razão pela qual mais estudos são necessários para esclarecer a importância relativa de diferentes tipos de estresses sobre o desempenho e dinâmica de populações de plantas em pastagens.

\section{AGRADECIMENTOS}

À Fundação Coordenação de Aperfeiçoamento de Pessoal de Nível Superior (CAPES), pela concessão de bolsa de Mestrado. À Fundação de Amparo à Pesquisa do Estado de São Paulo (FAPESP), pelo suporte financeiro da área experimental.

\section{REFERÊNCIAS BIBLIOGRÁFICAS}

ALMEIDA, E.X.; SETELICH, E.A.; MARASCHIN, G.E. Oferta de forragem e variáveis morfogenéticas em capim-elefante anão cv. Mott. In: REUNIÃO ANUAL DA SOCIEDADE BRASILEIRA DE ZOOTECNIA, 34., Juiz de Fora, 1997. Anais. Juiz de Fora: SBZ, 1997. p.240-242.

BINNIE, R.C.; CHESTNUTT, D.M.B. Effect of continuous stocking by sheep at four sward heights on herbage mass, herbage quality and tissue turnover on grass/clover and nitrogenfertilized grass swards. Grass and Forage Science, v.49, p.192-202, 1994.

BIRCHAM, J.S.; HODGSON, J. The influence of sward condition on rates of herbage growth and senescence in mixed swards under continuous stocking management. Grass and Forage Science, v.38, p.323-331, 1983.

BRASIL. Ministério da Agricultura. Serviço Nacional de Pesquisa Agronômica. Comissão de Solos. Levantamento de reconhecimento dos solos do estado de São Paulo. Rio de Janeiro, 1960. 634p. (Boletim, 12).

CARNEVALLI, R.A.; Da SILVA, S.C. Validação de técnicas experimentais para avaliação de características agronômicas e ecológicas de pastagens de Cynodon dactylon cv. 'CoastCross-1'. Scientia Agricola, v.56, p.489-499, 1999.

CARVALHO, C.A.B. Padrões demográficos de perfilhamento e acúmulo de forragem em pastagens de Cynodon spp. manejadas em quatro intensidades de pastejo. Piracicaba, 2000. 96p. Dissertação (Mestrado) - Escola Superior de Agricultura "Luiz de Queiroz", Universidade de São Paulo. 
Da SILVA, S.C. A study of spring management effect on summerautumn pasture and milk production of perennial ryegrass $\mathrm{x}$ white clover dairy swards. Palmerston North, 1994. 217p. Thesis (Ph.D.) - Massey University.

Da SILVA, S.C.; PEDREIRA,C.G.S. Princípios de ecologia aplicados ao manejo da pastagem. In: SIMPÓSIO SOBRE ECOSSISTEMA DE PASTAGENS, 3., Jaboticabal, 1997. Anais. Jaboticabal: FUNEP, 1997. p.1-62.

GOMIDE, C. A. M.; GOMIDE, J.A.; QUEIROZ, D. S.; PACIULLO, D. S. C. Fluxo de tecidos em Brachiaria decumbens. In: REUNIÃO ANUAL DA SOCIEDADE BRASILEIRA DE ZOOTECNIA, 34., Juiz de Fora, 1997. Anais. Juiz de Fora: SBZ, 1997. p.117-119.

GRANT, S.A.; BARTHRAM, G.T.; TORVELL, L.; KING, J.; ELSTON, A. Comparision of herbage production under continuous stocking and intermittent grazing. Grass and Forage Science, v.43, p.29-39, 1988.

HEPP, C.; MILNE, A.; ILLIUS, A.W.; ROBERTSON, E. The effect of summer management of perennial ryegrass-dominant swards on plant and animal responses in the autumn when grazed by sheep: 1. Tissue turnover and sward structure. Grass and Forage Science, v.51, p.250-259, 1996.

HODGSON, J. Grazing management: science into practice. Essex: Longman Scientific \& Technical, 1990.

LEMAIRE, G.; AGNUSDEI, M. Leaf tissue turn-over and efficiency of herbage utilization. In: SIMPÓSIO INTERNACIONAL "GRASSLAND ECOPHYSIOLOGY AND ECOLOGY", 1., Curitiba, 1999. Anais. Curitiba: UFPR, 1999. p.165-183.

LEMAIRE, G.; CHAPMAN, D. Tissue flows in grazed plant communities. In: HODGSON, J.; ILLIUS, A.W. (Ed.) The ecology and management of grazing systems. Guildford: CAB International, 1996. cap.1, p.3-36.

MARASCHIN, G.E. Manejo de "Coast-Cross" - 1 Sob Pastejo. In: WORKSHOP SOBRE O POTENCIAL FORRAGEIRO DO GÊNERO Cynodon, Juiz de Fora, 1996. Anais. Juiz de Fora: EMBRAPA, CNPGL, 1996. p.93-110.

MORALES, A.; NABINGER, C.; ROSA, L.M.; MARASCHIN, G.E. Efeito da limitação hídrica sobre a morfogênese e repartição da biomassa de Lotus corniculatus L. cv. São Gabriel. In: REUNIÃO ANUAL DA SOCIEDADE BRASILEIRA DE ZOOTECNIA, 34., Juiz de Fora, 1997. Anais. Juiz de Fora: SBZ, 1997. p.124-126.
OLIVEIRA, M.A.; PEREIRA, O.G.; GARCIA, R.; HUAMAN, C.A.M.; SILVEIRA, P.R. Morfogênese de folhas do Tifton-85 (Cynodon spp.) em diferentes idades de rebrota. In: REUNIÃO ANUAL DA SOCIEDADE BRASILEIRA DE ZOOTECNIA, 35. Botucatu, 1998. Anais. Botucatu: SBZ, 1998. p.302-303.

OMETTO, J.C. Registros e estimativas dos parâmetros meteorológicos da região de Piracicaba, S.P. Piracicaba: FEALQ, 1989. 76p.

PARSONS, A.J. The effects of season and management on the growth of grass swards. In: JONES, M.B.; LAZEMBY A. (Ed.) The grass crop: the physiological basis of production. London: Chapman \& Hall, 1988. p.129-177.

PARSONS, A.J.; LEAFE, E.L.; COLLET, B.; PENNING, P.D.; LEWIS, J. The physiology of grass production under grazing II. Photosynthesis, crop growth and animal intake of continuously-grazed swards. Journal of Applied Ecology, v.20, p.127-139, 1983.

PINTO, J.C.; GOMIDE, J.A.; MAESTRI, M.; LOPES, N.F. Crescimento de folhas de gramíneas forrageiras tropicais, cultivadas em vasos, com duas doses de nitrogênio. Revista da Sociedade Brasileira de Zootecnia, v.23, p.327-332, 1994.

SAS Institute. SAS user's guide: release. 6.03. Cary: Statistical Analysis System Institute, 1988. 1028p.

SBRISSIA, A.F. Compensação tamanho/densidade populacional de perfilhos em pastagens de Cynodon spp. Piracicaba, 2000. 80p. Dissertação (Mestrado) - Escola Superior de Agricultura "Luiz de Queiroz", Universidade de São Paulo.

XIA, J.X.; HODGSON, J.; CHU, A.C.P. Effects of severity of grazing on tissue turnover in Matua prairie grass dairy pasture. New Zealand Journal of Agricultural Research, v.37, p.41-50, 1994

YOUNGNER, V.B. The biology and utilization of grasses. In: YOUNGNER, V.B.; MACKELL, C.M. (Ed.) Physiological ecology. New York: Academic Press, 1972. cap.6, p.167-168.

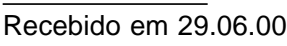

